\title{
Simian virus 40 and human pleural mesothelioma
}

\author{
C Mulatero, T Surentheran, J Breuer, R M Rudd
}

Department of Medical Oncology

C Mulatero

R M Rudd

\section{Department of Virology \\ T Surentheran \\ J Breuer}

St Bartholomew's Hospital, London EC1A 7BE, UK

Correspondence to: Dr R M Rudd.

Received 14 May 1998 Returned to authors 29 June 1998

Revised version received 10 September 1998

Accepted for publication 23 September 1998

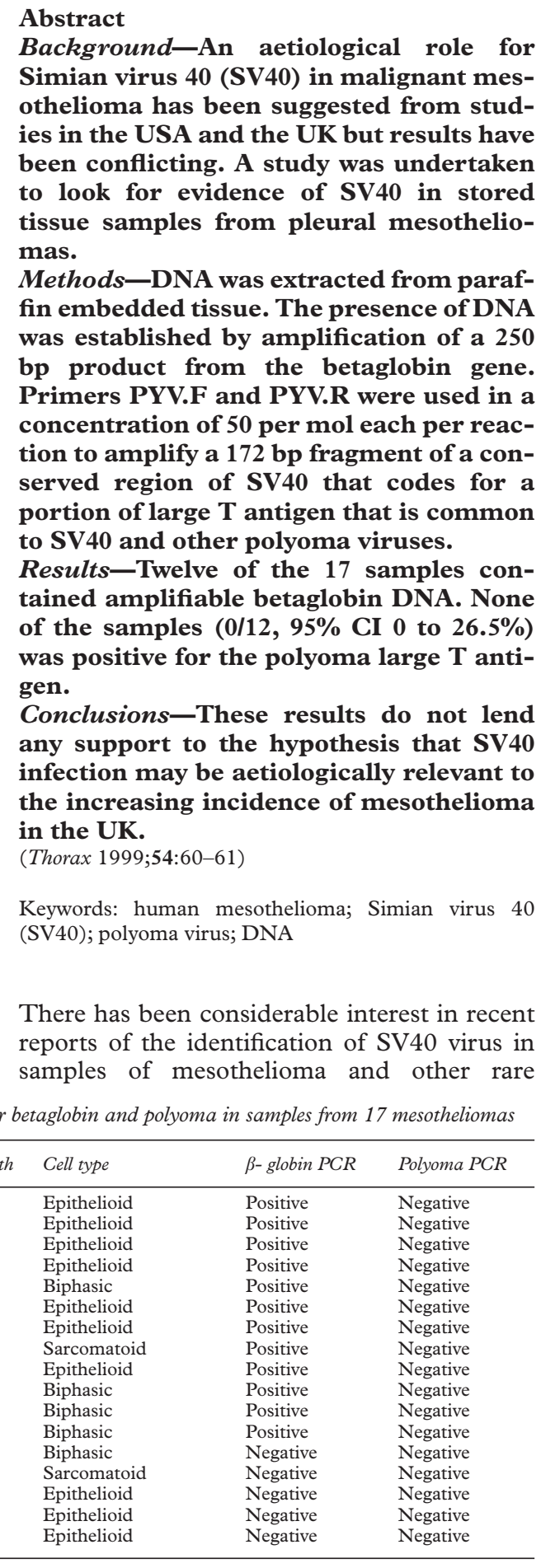

tumours. ${ }^{1-4}$ This virus contaminated Salk polio vaccine grown on monkey kidney culture from 1954 to 1961 and various other vaccines used in smaller quantities, including early samples of oral polio vaccine, although commercial Sabin vaccine was free from contamination. ${ }^{5}$ The incidence of mesothelioma in the UK is continuing to increase and is expected to do so until 2020. ${ }^{6}$ This increase can be adequately explained on the basis that the peak use of asbestos without respiratory protection was around 1970, but it has been suggested that the SV40 virus could have an aetiological role. ${ }^{12}$

We sought evidence of SV40 in stored samples from patients with mesothelioma presenting to our institution between 1995 and 1996.

\section{Methods}

Paraffin sections of pleural biopsy tissue from 17 patients with a diagnosis of pleural mesothelioma, confirmed histologically with supportive immunohistochemistry, were analysed. All patients gave a history of exposure to asbestos. Further demographic details and results are shown in table 1. DNA was extracted with phenol chloroform after five days of proteinase $\mathrm{K}$ digestion and precipitated with ethanol. The presence of DNA was established by amplification of a $250 \mathrm{bp}$ product from the betaglobin gene. Subsequently, $200 \mathrm{ng}$ of DNA was amplified in $50 \mu \mathrm{l}$ of reaction mix containing buffer (100 M Tris $\mathrm{HCl}, 500 \mathrm{mM} \mathrm{KCl}$; Perkin Elmer), magnesium chloride $(1.5 \mathrm{mM})$, dNTPs (200 $\mu \mathrm{M}$ each), amphilitaq polymerase (1 unit). Primers PYV.F and PYV.R were used at a concentration of 50 per mol each per reaction to amplify a $172 \mathrm{bp}$ fragment of a conserved region of SV40 that codes for a portion of large $\mathrm{T}$ antigen that is common to SV40, BK, and JC viruses. ${ }^{3}$ A positive plasmid control (100 copies per cell) and a negative control were included with each amplification. The reaction mix was denatured at $94^{\circ} \mathrm{C}$ for one minute and then subjected to 40 cycles of $94^{\circ} \mathrm{C}$ for one minute, $52^{\circ} \mathrm{C}$ for one minute, $72^{\circ} \mathrm{C}$ for one minute, and a final cycle of $72^{\circ} \mathrm{C}$ for 10 minutes. Primers were assayed against plasmid containing SV40 large T antigen with human placental DNA. The sensitivity of detection was estimated at $1-10$ genome copies or 1 copy per cell when plasmid was diluted in human placental DNA. Reactions which were negative for polyoma and betaglobin were spiked with 1000 copies of plasmid containing 
the gene for polyoma large $\mathrm{T}$ antigen and reamplified to detect inhibitors. The electrophoresis method was standard agarose gel electrophoresis at $80-100 \mathrm{~V}$ with ethidium bromide staining.

\section{Results}

Twelve of the 17 samples contained amplifiable betaglobin DNA. None of the samples $(0 / 12$, $95 \%$ CI 0 to $26.5 \%$ ) was positive for the polyoma large $\mathrm{T}$ antigen. None of the PCR reactions was inhibitory.

\section{Discussion}

SV40 is an oncogenic virus in animal models and recently there has been interest in the possibility that it may be relevant to the increasing incidence of human mesothelioma. ${ }^{12}$ Previous studies from the $\mathrm{USA}^{3}$ and the $\mathrm{UK}^{4}$ have identified evidence of SV40 virus in mesothelioma samples. Like Pepper et $a l,{ }^{4}$ we used archival material and found it possible to extract DNA from the majority of paraffin embedded tissue samples. We used the PYV.F and PYV.R primers because they are more sensitive for detection of SV40-like DNA sequences than primers specific for SV40. ${ }^{3}$ The sensitivity of the assay was estimated at one copy of target sequence per cell. This is comparable to the sensitivity reported by Strickler et $a l^{\prime}$; others have not reported sensitivity. ${ }^{34}$ The sensitivity of the assay is the same as that of an assay which detects papillomavirus in cervical carcinoma from similar material prepared in the same way in the same laboratory, and we are therefore confident that our results were truly negative.

Carbone and colleagues ${ }^{3}$ reported SV40-like DNA sequences in 29 of 48 mesotheliomas (60\%, 95\% CI 45 to 74\%). Pepper et $a l^{4}$ found PYV positivity in six of nine mesotheliomas $(67 \%, 95 \%$ CI 30 to $93 \%)$ and, of these, SV 40 specific large $\mathrm{T}$ antigen was positive in four ( $44 \%, 95 \%$ CI 14 to $79 \%)$. While the number we tested was small, the $95 \%$ confidence interval (0 to $26.5 \%$ ) does not overlap that reported in the two series with positive results for SV40. We can therefore be reasonably confident that our results represent a true difference from the positive results reported previously. A larger series from the USA found negative results in all of 48 betaglobin positive mesothelioma samples (95\% CI 0 to $7.4 \%$ ) using two SV 40 primer sets with an analytical sensitivity of 1-10 genome copies. ${ }^{7}$ The explanation for the conflicting findings is not obvious, but possi- bilities include false positive results due to laboratory contamination of samples, differences in methods used to harvest DNA from paraffin embedded tissue, and geographical variation in frequency of SV40 infection.

Human SV40 infection by natural routes has not been demonstrated and transmission via contaminated polio vaccine has been postulated as an explanation for the presence of SV40 in tumour tissue. However, patients with childhood ependymomas and choroid plexus tumours in which SV40 has also been identified were too young to have received the contaminated polio vaccine, ${ }^{2}$ and some of the mesothelioma patients reported positive were too old for it to be likely that they would have received the vaccine. ${ }^{34}$ It has been estimated that $62 \%$ of the US population under 60 , including $90 \%$ of those under 20 , had been immunised by potentially infected vaccine by the time the problem was recognised. ${ }^{5} \mathrm{~A}$ recent retrospective cohort study in the USA found no evidence of an excess of mesotheliomas or other tumours such as ependymomas and osteosarcomas suggested to be possibly linked with SV40 in birth cohorts likely to have received SV40 contaminated polio vaccine. ${ }^{8}$ The theoretical possibility remains that SV40 may operate on the pleura only as a cocarcinogen with asbestos, which could give rise to a more limited impact on the incidence of mesothelioma. However, our results do not lend any support to the hypothesis that SV40 infection may be aetiologically relevant to the increasing incidence of mesothelioma in the UK

Funding: Special Trustees for St Bartholomew's Hospital.

1 Hubbard R. The aetiology of mesothelioma: are risk factors other than asbestos exposure important? Thorax 1997;52:496-7.

2 Stenton SC. Simian virus 40 and human malignancy. BMF 1998;316:877.

3 Carbone M, Pass HI, Rizzo P, et al. Simian virus 40-like DNA sequences in human pleural mesothelioma. Oncogene 1994;9:1781-90.

4 Pepper C, Jasani B, Navabi H, et al. Simian virus 40 large T antigen (SV40LTAg) primer specific DNA amplification in human pleural mesothelioma tissue. Thorax 1996;51:10746.

5 Shah K, Nathanson N. Human exposure to SV40: review and comment. Am F Epidemiol 1976;103:1-12.

6 Peto J, Hodgson JT, Matthews FE, et al. Continuing increase in mesothelioma mortality in Britain. Lancet 1995;345: 535-9.

7 Strickler HD, Goedert JJ, Fleming M, et al. Simian virus 40 and pleural mesothelioma in humans. Cancer Epidemiol Biomarkers Prev 1996;5:473-5.

8 Strickler HD, Rosenberg PS, Devesa SS, et al. Contamination of poliovirus vaccines with simian virus 40 (19551963) and subsequent cancer rates. fAMA 1998;279:292- 